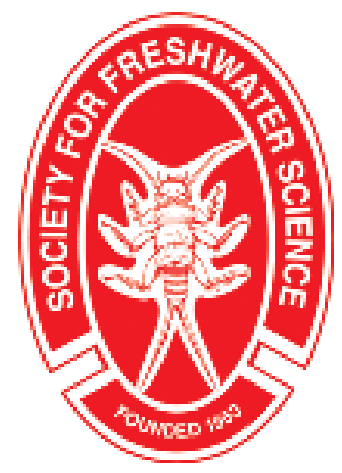

Odonata as candidate macroecological barometers for global climate change Author(s): Christopher Hassall

Source: Freshwater Science, (-Not available-), p. 000

Published by: The University of Chicago Press on behalf of Society for Freshwater Science

Stable URL: http://www.jstor.org/stable/10.1086/682210

Accessed: 26/05/2015 20:15

Your use of the JSTOR archive indicates your acceptance of the Terms \& Conditions of Use, available at http://www.jstor.org/page/info/about/policies/terms.jsp

JSTOR is a not-for-profit service that helps scholars, researchers, and students discover, use, and build upon a wide range of content in a trusted digital archive. We use information technology and tools to increase productivity and facilitate new forms of scholarship. For more information about JSTOR, please contact support@jstor.org. 


\title{
Odonata as candidate macroecological barometers for global climate change
}

\author{
Christopher Hassall ${ }^{1,2}$ \\ ${ }^{1}$ School of Biology, University of Leeds, Woodhouse Lane, Leeds LS2 9JT UK
}

Abstract: Many investigators have described a footprint of global environmental change in macroecological trends across multiple taxa. However, little comparative analysis has been done to evaluate whether some taxa are responding more than others. I tested 2 hypotheses: 1) taxa vary strongly in terms of range shifts and phenological advances in their responses to changing climate, and 2) taxa that shift ranges also advance phenology. I used an initial database of $>4$ million recorded sightings of UK animal species from 24 orders and found descriptions of range shifts for 612 species and phenological trends for 923 species. I compared the 2 responses for 464 species and found wide variation in the extent to which taxa are responding. Vertebrate taxa were the least well recorded and showed weak or nonsignificant responses. Invertebrates were well recorded and responded strongly in range and phenology, but evidence of an association between range shifts and phenological advances was equivocal. My results show that different taxa are exhibiting different responses to the same environmental change, and that mechanistic and traits-based studies may reveal the causes of that variation. Spatial responses may be constrained by mode of dispersal, and insects and arachnids typically respond strongly, whereas terrestrial vertebrates do not. Phenological responses are complex and may involve species-specific physiological relationships between development and seasonal cues. Use of a model taxon could increase efficiency of monitoring regimes by simplifying monitoring targets and techniques. Potential exists for $\geq 1$ taxa to be indicators of climate change, whereby the responses of one or a group of species could be used to infer changes at a broader taxonomic scale. I highlight Odonata as a taxon that responds strongly in multiple modalities, is charismatic enough to appeal to citizen scientists, and is an emerging physiological and genetic model.

Key words: range shift, phenology, climate change, temperature, global warming, Odonata, dragonfly, damselfly, UK, historical records

Global environmental change has reached such a pace now that a strong argument can be made to consider the current period as the Anthropocene: an era in which the dominant force acting on the world is humankind (Crutzen 2006). Among the many anthropogenic stressors that affect the world's biota are creation of novel compounds (e.g., chlorofluorocarbons), burning of large amounts of fossil fuels, and alteration of land use via removal of natural communities and replacement with artificial communities (particularly in agriculture). These stressors are creating substantial challenges for biodiversity conservation. Climate change poses more of a threat in high-latitude and high-altitude regions, whereas landuse change is predicted to exert a greater effect in temperate and low-elevation areas (Sala et al. 2000).

Some of the best-studied impacts of environmental change are the biological effects of changing climate (reviewed by Parmesan 2006), and most $20^{\text {th }}$-century climate change can be attributed to human action (Huber and Knutti 2011). Phenologies are advancing, such that species appear earlier in the year (Menzel et al. 2006). These temporal shifts can significantly affect trophic relationships where prey and predator become decoupled in time (Winder and Schindler 2004, Visser et al. 2006). In addition to temporal shifts, spatial shifts also have been well documented, particularly in taxa for which historical records provide baseline distributional data against which to compare contemporary distributions (Hickling et al. 2006). These distributional shifts raise substantial issues for the protection of global biodiversity, which frequently involves the designation of static reserves in which to conserve species. Previous investigators have suggested that at least some species might shift their ranges to entirely new areas (Araújo et al. 2004, Thomas et al. 2004, Li et al. 2006), but many sources of error are associated with attempting to plan for conservation in a changing world (Pressey et al.

E-mail address: ${ }^{2}$ c.hassall@leeds.ac.uk

DOI: 10.1086/682210. Received 10 June 2014; Accepted 2 December 2014; Published online 20 May 2015.

Freshwater Science. 2015. 34(3):000-000. ๑ 2015 by The Society for Freshwater Science. 
2007). Last, authors of recent reviews have argued that a $3^{\text {rd }}$ large-scale effect of climate is a global reduction in body size under increasing temperatures (Daufresne et al. 2009). Such a pattern, if it is truly universal, could have wide-reaching impacts on a variety of taxa and the ecosystem services that they provide (Sheridan and Bickford 2011). However, wider taxonomic surveys have shown that-as with distributional and phenological responsesthis 'rule' has a number of exceptions (Gardner et al. 2011).

The capacity of biodiversity to persist in a changing world in the long term is of great interest to conservation biologists. Reasonable evidence indicates that preAnthropocene climatic shifts elicited similar changes in distributions in some taxa (Coope 1995, 2004, Ashworth 1997), and Balmford (1996) suggested that past stressors, such as climate change, constitute 'evolutionary filters' that have eliminated those taxa without the capacity to deal with climate change. However, contemporary anthropogenic stressors do not act in isolation but interact, often synergistically. These interactions may nullify pre-existing adaptations that have allowed taxa to survive past climatic shifts. For example, habitat fragmentation may compromise a species' ability to shift its distribution in response to changing temperature (Travis 2003), changing weather patterns may alter disease dynamics (Harvell et al. 2002), and fire suppression may influence the impacts of invasive species on native plant communities (MacDougall and Turkington 2005). These factors may explain why we fail to observe a truly consistent response to climate change across taxa.

Two key questions emerge from these observations. First, should we expect all taxa to respond in all possible ways to climate to secure long-term persistence? For example, if a species is capable of tracking shifts in the location of its fundamental niche (as Quaternary insects are thought to have done; Coope 2004), perhaps phenological responses are not needed. However, a correlated response to climate change across modalities (distribution, phenology, size) might be expected if a particular species has a strong reliance on temperature to maximize physiological efficiency (i.e., convergence of thermal dependence of different modalities), or if modalities share a common, thermally regulated mechanism that underlies the different response types.

Second, do taxa exist that respond in all of these ways and could be used as general barometers of climate change? In comparison to the abiotic factors that constitute the change, biological indicators offer a holistic approach to studying the ecological consequences of changing climate and a focus for applying limited conservation funds by acting as a proxy for the wider biota. To match the predicted responses in all 3 areas, a biological barometer would have a range that is shifting poleward, phenology that is advancing in response to increasing temperature, and body size that is declining with increasing temperature. A taxon capable of responding in all 3 modalities would provide a theoretical baseline against which to evaluate the responses of other taxa and the factors that may prevent those other taxa from responding.

I focused this study on the Odonata (dragonflies and damselflies) as a candidate barometer for climate change. Odonata show poleward shifts (Hickling et al. 2005, Hassall and Thompson 2010), phenological advances (Hassall et al. 2007), and reduced body size (De Block and Stoks 2003) at increasing temperatures and are heavily influenced by environmental temperature change (for a review see Hassall and Thompson 2008). However, large-scale geographical studies of odonate body size suggest that an interaction between temperature and photoperiod-mediated time stress operates in the field to create U-shaped latitudesize relationships (Johansson 2003, Hassall 2013). Odonata also are a model system for a variety of questions in ecology and evolution (Córdoba-Aguilar 2008), including effects of other anthropogenic stressors, such as habitat fragmentation (Watts et al. 2004), environmental pollution (Van Praet et al. 2012), and landuse change (both agricultural: Raebel et al. 2012, and urban: Goertzen and Suhling 2013).

I focused my analysis geographically on the distributional and phenological response of British animal taxa to recent climate change. I analyzed data with consistent and evidence-based methods to account for heterogeneity in biological records and used the results to test 2 hypotheses: 1) taxa vary strongly in their response to changing climate in terms of range shifts and phenological advances, and 2) taxa that shift ranges also advance phenology. Last, I considered potential candidates for barometers of climate change based on those results.

\section{METHODS \\ Biological records}

I downloaded data from 28 biological recording schemes via the National Biodiversity Network (NBN) Gateway, which contains $>4$ million records (access date for all data was 28 May 2013). The list of schemes, number of records and species in each, and a link to the schemes on the NBN Gateway can be found in Table S1. Each record in each data set represents an individual sighting of a species and includes the date and location of that sighting. I excluded records with $<10-\mathrm{km}$ precision on the geographical coordinates of the sighting and records without a date. For the remaining records, I converted dates to ordinal dates (days since 1 January) and Ordnance Survey coordinates (the standard system for recording biological sightings in the UK) to eastings and northings on the British National Grid (the number of meters north and east of an origin in the southwestern corner of the British Isles). 


\section{Range-shift analysis}

To quantify the movement of each species under climate change, I selected 2 time periods from the records: 1960-1969 and 1990-1999. I chose these time periods for 2 reasons. First, a preliminary evaluation of the records showed a reasonable degree of recording of most focal taxa during these periods. Second, use of samples from the standardized time periods helps to prevent problems associated with different climatic patterns in different periods that can arise when periods used differ among taxa (e.g., Hickling et al. 2006). This choice to standardize time periods may have led to some sacrifice in terms of absolute number of records for some taxa, but ensuring that data are comparable takes precedence in an explicitly comparative analysis, such as this.

I extracted records in each time period for each species. I included species only if $>45$ records were present in each time period (Table 1) because this threshold number is needed to compensate for the noise associated with low numbers of records (Hassall and Thompson 2010). The range margin in each period was taken to be the average of the 10 most-northern grid squares in which each species was recorded. The difference in the location of that margin, measured in $\mathrm{km}$ using the British National Grid, was the range shift for that species. Predicted range shifts can be estimated if species are matching climate change perfectly because isotherms (and, hence, the location of an organism's fundamental thermal niche) move $150 \mathrm{~km}$ poleward per $1^{\circ} \mathrm{C}$ increase in temperature (IPCC 1996). Mean annual temperatures were calculated based on the central England temperature series (UK Meteorological Office Hadley Centre 2006). The difference between the lowest of the mean annual temperatures for the $10 \mathrm{y}$ in the $1^{\text {st }}$ period $\left(7.45^{\circ} \mathrm{C}\right)$ and the highest mean annual temperature for the $10 \mathrm{y}$ in the $2^{\text {nd }}$ period $\left(9.41^{\circ} \mathrm{C}\right)$ yields an estimated maximum isotherm shift of $294 \mathrm{~km}$. The difference between the average mean annual temperatures of each period (1960-1969: 8.16 $\left.{ }^{\circ} \mathrm{C} ; 1990-1999: 8.92^{\circ} \mathrm{C}\right)$ gives an estimated mean isotherm shift of $114 \mathrm{~km}$.

\section{Phenology-shift analysis}

To quantify changing phenology for each species, I grouped records taken between 1960 and 1999 by the year of the record and calculated the $5^{\text {th }}$ percentile of the distribution of records for each year. These data consist of distributional records with date recorded next to the location. This approach is a less accurate method than standardized surveys to detect changing phenology, but distributional records can provide a reasonable estimate of phenology (Bishop et al. 2013). Percentile sighting dates are more robust estimators of phenological variation than absolute sighting dates (Moussus et al. 2010). I excluded years with $<30$ records and species with $<3$ y (Table 1 ). I used mean annual temperature from the central England temperature series as a general indicator of temperature in each year.

I used a Pearson correlation to calculate the strength and direction of the relationship between the $5^{\text {th }}$-percentile sighting dates and annual temperature for each species. I summarized species' responses to the order level with a meta-analytical approach. I converted Pearson's correlation coefficients to Fisher's $z$-scores with the $z 2 r$ function in the psychometric package (Fletcher 2010) in $\mathrm{R}$ (R Project for Statistical Computing, Vienna, Austria) with standard errors (SEs) calculated as SE $=1 / \sqrt{ }(n-3)$, where $n$ is the number of years of data for each species. I used these $z$-scores and SEs in the metagen function in the meta package (Schwarzer 2014) in $\mathrm{R}$ to produce an estimate of the overall effect size with upper and lower 95\% confidence intervals (CIs). Effect sizes and CIs were then back-converted into Pearson's $r$ statistics using the $z 2 r$ function in psychometric. In the case of phenological changes, no clear expectation exists for a given advance in phenology/ unit temperature.

\section{Statistical analysis}

I used the data to ask 3 questions. First, what is the mean distributional response of British animal taxa to climate change, and which taxa deviate from that mean? Species that do not deviate from the mean can be said to be representative of the overall trends. I used a 1-sample $t$-test to test whether the distribution of range shifts for each of the taxa differed from the mean value for all taxa. I used both the average among species and the average among orders to provide a partial control for phylogeny and the unevenness of species numbers across taxa. Second, what is the mean phenological trend in British animal taxa? Again, species that do not deviate significantly from that mean trend can be said to be representative of the broader pattern. I used a 1-sample $t$-test to test whether the distribution of Pearson correlation coefficients describing phenology-temperature relationships for each taxon differed from the mean value for all taxa (averages across species and orders). Third, are taxa that are shifting their ranges also advancing their phenology? I created a mixedeffects model with range shift as the response (chosen arbitrarily), phenology correlation coefficient as a continuous predictor, and taxonomic group as a random effect with the lmer function in the lme4 package (Bates et al. 2011) in $\mathrm{R}$ to analyze the relationship between the 2 responses. Statistical significance of the fixed effect was evaluated using the pamer.fnc function in the LMERConvenienceFunctions package (Tremblay and Ransijn 2013) in R, and the statistical significance of the random effect was evaluated using the exactRLRT function in the RLRsim package (Scheipl et al. 2008) in R. 


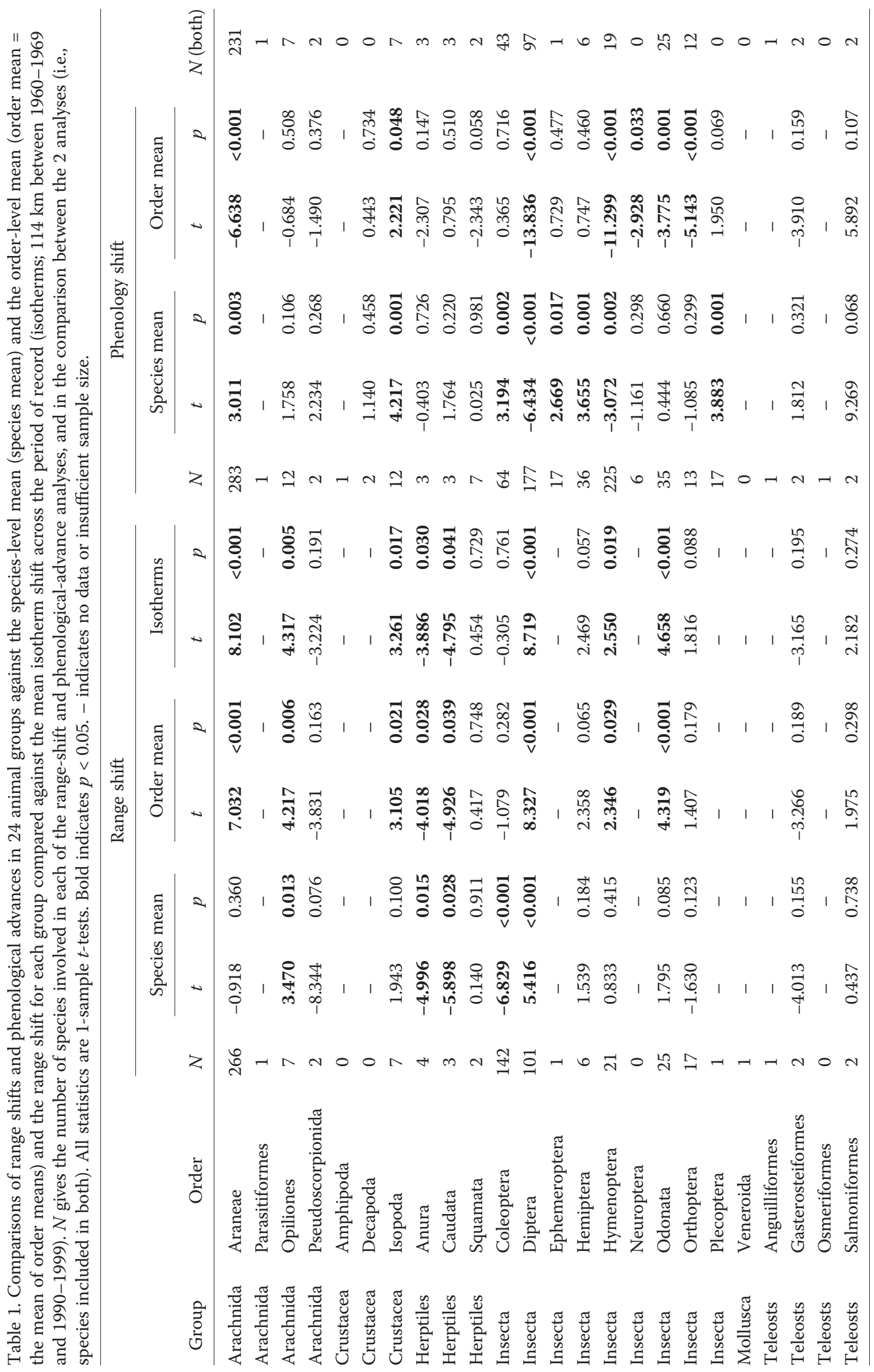




\section{RESULTS}

\section{Biological records}

The total numbers of species included in the analyses ( $n=612$ for the range-shift analysis, $n=923$ for the phenology analysis, $n=464$ for the comparison between range shift and phenology) were far lower than the number of species for which there were records in the data sets $(n=$ 5185). The average number of records/species for the 5185 total species was 735 , but the median was only 48 and 1473 species had $<10$ records. Of the 20 most-recorded species (all with $>21,000$ records), 15 were Odonata, including Ischnura elegans, which was the most-recorded species $(96,555$ records).

\section{Range-shift analysis}

The mean range shift recorded across all 612 species was $177.9 \pm 6.2 \mathrm{~km}$, considerably higher than the $114-\mathrm{km}$ isotherm shift predicted from the difference in mean annual temperatures between the 2 time periods but lower than the 294-km isotherm shift predicted by the maximum annual temperature difference. However, the mean shift when averaging across orders was $121.5 \pm 34.6 \mathrm{~km}$. Species varied strongly in whether they shifted ranges less than, the same as, or more than the average (Table 1, Fig. 1). The shifts of 10 taxa, including the Odonata and Hymenoptera (which are among the best-recorded taxa), did not differ from the overall species average. However, Odonata, Hymenoptera, and 6 other taxa, shifted at a different rate relative to the mean across orders. The results suggest that several groups are advancing ahead of the mean range shift predicted from the isotherms, whereas the Anura and Caudata (represented by relatively few species) are showing significantly lower rates of expansion.

\section{Phenology-shift analysis}

The mean Pearson correlation coefficient for the relationship between $5^{\text {th }}$-percentile sighting date and temperature across 923 species was $-0.252 \pm 0.014$. Linear regressions carried out on the same 923 species gave an average rate of change in $5^{\text {th }}$-percentile sighting dates of $-6.691 \pm 0.830 \mathrm{~d} /{ }^{\circ} \mathrm{C}$. However, the mean shift when averaging across orders was $-0.065 \pm 0.059$, corresponding to an average rate of change of $-0.912 \pm 2.770 \mathrm{~d} /{ }^{\circ} \mathrm{C}$. Sixteen of the 23 taxa exhibited phenological shifts that were, on average, not different from 0 (Table 1, Fig. 2), whereas the remaining 7 taxa, including the Odonata, exhibited significant phenological advances.

\section{Comparison between range and phenology}

The mixed-effects model describing the relationship between range shift and phenology shift while taking into account taxonomy showed a marginally significant positive relationship between the 2 responses $(F 1,463=4.151, p=$

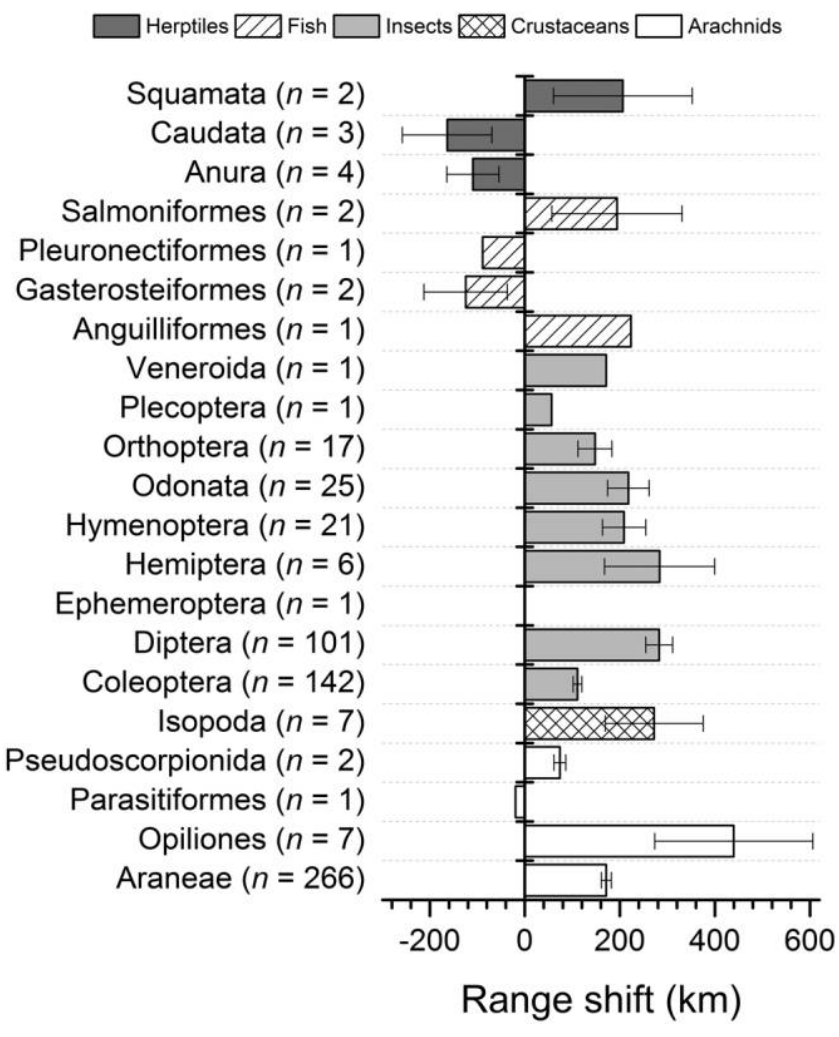

Figure 1. Mean $( \pm 1$ SE) distance and direction of range shifts between 1960 and 1999 in 21 British animal groups: herptiles $(n=3)$, fish $(n=4)$, insects $(n=9)$, crustaceans $(n=1)$, and arachnids $(n=4)$.

0.042). Such a relationship runs counter to the negative relationship that would be expected if species that were advancing phenology more consistently (a negative correlation of increasing magnitude) also were shifting their range to a greater extent (a positive shift of increasing magnitude). However, this relationship accounts for only $0.73 \%$ of the deviance in the response variable. The random effect of order was highly significant $(\mathrm{LR}=74.150, p<$ 0.001). A visual analysis of the results (Fig. 3) suggests a number of more-nuanced patterns. Most vertebrate taxa, which were relatively poorly recorded in the data sets, tended to show little consistency in their responses, although reptiles showed both an advance in phenology and a poleward range shift. However, a number of well recorded invertebrate taxa, including the Odonata, Diptera, Orthoptera, Hymenoptera, and Araneae, showed strong and consistent advances in phenology and poleward range shifts. Within taxa, the only group to show a statistically significant interspecific correlation between phenology and distributional change were the Araneae $(n=231, r=0.207$, $p=0.002)$. Of the remaining taxa with $>10$ species for comparison, 5 showed positive relationships between phenology and distributional shift (Hymenoptera: $n=19, r=0.129$, $p=0.599$; Coleoptera: $n=43, r=0.140, p=0.370$; Diptera: 


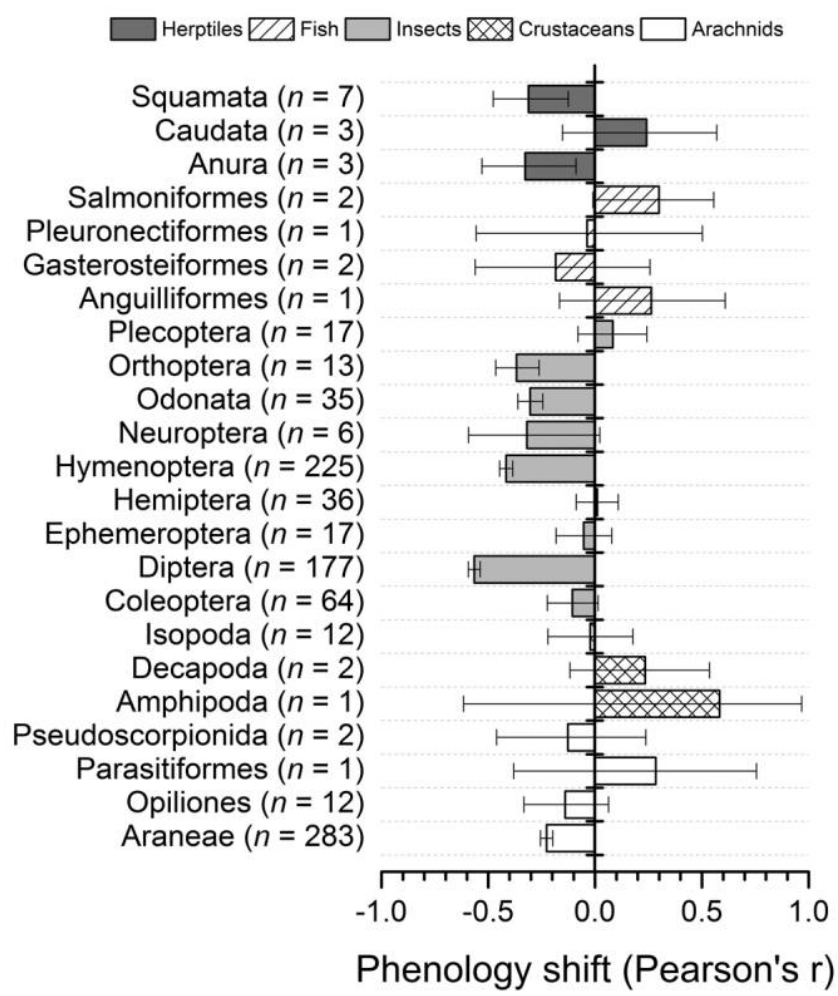

Figure 2. Mean (95\% confidence interval associated with the estimate of total effect size for each group [see text for details]) correlation coefficient showing the strength and direction of the relationship between $5^{\text {th }}$-percentile sighting date and temperature in 23 British animal groups: herptiles $(n=3)$, fish $(n=4)$, insects $(n=9)$, crustaceans $(n=3)$, and arachnids $(n=4)$. Numbers in brackets correspond to the number of species in each group for which data were available.

$n=97, r=0.038, p=0.715)$ and 2 showed negative relationships (Orthoptera: $n=12, r=-0.219, p=0.494$; Odonata: $n=25, r=-0.238, p=0.252)$.

\section{DISCUSSION}

Authors of a large number of studies have focused on describing specific trends in biological responses to climate change, and others have synthesized average effects to demonstrate the consistency of biological responses (Walther et al. 2002, Parmesan and Yohe 2003), but few have attempted to compare large-scale taxonomic responses or to compare different response types in the same taxa. Results from my study demonstrate wide variation in the responses from UK fauna and that even those taxa that do seem to be responding are responding to varying extents. The vertebrate taxa represented in the data set appear to be exhibiting lower responses than invertebrate taxa in terms of distributional and phenological shifts. However, several invertebrate taxa are exhibiting consistent shifts in line with what would be expected from changing temperatures.
Interspecific variability in certain responses to climate change has been studied extensively in some groups. For example, advances in phenology are greater in butterflies with narrower larval diet breadth and more advanced overwintering stages (Diamond et al. 2011), Odonata that do not diapause in the egg stage (Hassall et al. 2007), perennial plants (Crimmins et al. 2009), and lower trophic levels (Thackeray et al. 2010). Greater shifts in distribution tend to be found in Odonata with exophytic oviposition habits (Angert et al. 2011) and butterflies with greater dispersal ability and greater habitat availability (Pöyry et al. 2009). Investigators searching for traits that modulate range shifts in plants have been unsuccessful (Angert et al. 2011, Crimmins et al. 2011, Zhu et al. 2012). The patterns that do exist suggest a role for functional traits that cross large taxonomic boundaries, indicating that we might expect a similar response from all taxa. Recent efforts at predicting extinction risk under climate change have focused explicitly on life-history traits and spatial variables (Pearson et al. 2014).

Variability in responses to climate change among higher-level taxonomic groups is not surprising. In particular, evidence presented in my study that vertebrates are performing poorly in the context of the wider faunal response could be predicted from previous work showing widespread population declines in these taxa. Anura and

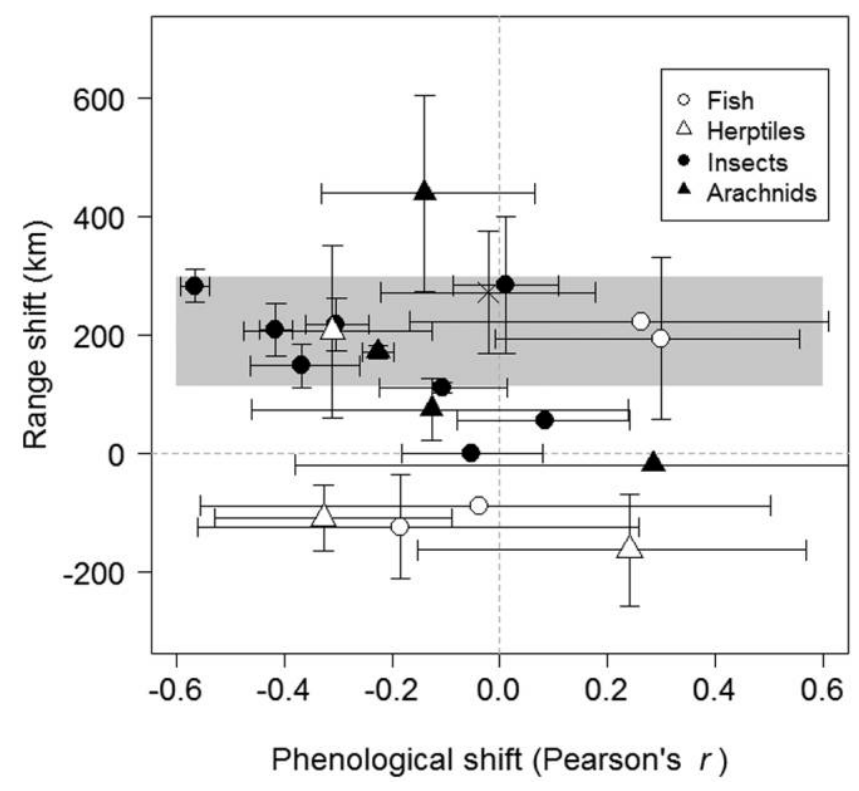

Figure 3. Mean $( \pm 1 \mathrm{SE})$ relationship between phenological responses (Pearson correlation between $5^{\text {th }}$-percentile sighting date and temperature) and range shifts (distance and direction moved at the range margin between 1960-1969 and 1990-1999) in 20 British animal groups: fish $(n=4)$, herptiles $(n=3)$, insects $(n=9)$, and arachnids $(n=4)$. Shaded area indicates the range shift expected if species were tracking the mean isotherm shift $(114 \mathrm{~km})$ to the maximum isotherm shift $(294 \mathrm{~km})$. 
Caudata exhibit lower rates of expansion than do invertebrate groups that often show aerial dispersal (either by flight in many insect groups or by ballooning in arachnids). For example, many of the remaining reptiles in Europe are endangered (Böhm et al. 2013), and intensification of farming in the $2^{\text {nd }}$ half of the $20^{\text {th }}$ century destroyed large areas of amphibian habitat (Beebee and Griffiths 2005). However, in some areas, fish are exhibiting community-level shifts that are consistent with tracking of isotherms, despite living in an inherently fragmented habitat (Daufresne and Boët 2007). These shifts in fish distribution could be the result of changing climate, but shifts in the composition of freshwater invertebrates are thought to have been brought about by increases in water quality rather than changing temperature (Durance and Ormerod 2009). Change in water quality complicates the interpretation of range shifts in semi-aquatic taxa and may explain why some groups (e.g., Odonata) are shifting their ranges at a higher rate than might be expected given increases in environmental temperature.

British plant species that do not advance their phenology to track climate show stronger distributional shifts (Amano et al. 2014). These patterns make intuitive sense: the evolution of a strong response in either phenology or distributional shifts will alleviate selective pressures related to climate, such that there is no need to evolve a secondary response. Most species in the data set of the present study appear to follow the pattern that a stronger range shift is associated with weaker phenological advance (and vice versa) (summarized by order in Table 1 ). However, the spiders are the only group for which both responses are significant and in the expected direction. In the Orthoptera and Odonata, the trend seems to be toward a greater phenological advance in species with greater poleward range shifts, but these results are not statistically significant. For both groups, the relationships between temperature and a wide range of physiological traits are very strong (Willott and Hassall 1998, Hassall and Thompson 2008).

Application of the indicator-taxa approach to environmental monitoring seems like a logical way to overcome limitations in our knowledge about the wider biological community and a lack of resources with which to measure it. However, this approach is often applied very broadly and with charismatic, rather than useful, taxa. Proper application should involve specific species-environment interactions (Fleishman and Murphy 2009). In the case of climate change, taxa can be judged as useful ecological indicators based on several clear criteria (Pearson 1994, Caro and O'Doherty 1999). The 2 criteria I used as indicators of changing environmental temperatures were shifts in the location of a taxon's poleward range margin and in the $5^{\text {th }}$-percentile sighting date. The timing of insect emergence is already a part of the UK suite of climate-change indicators (Cannell et al. 1999).
One criterion that is missing from most lists of criteria is public accessibility. The vast majority of the data used in my study were collected by citizen scientists and enthusiasts rather than by professional scientists. Citizen science is a growing field of study and a tool of increasing importance (Silvertown 2009), but taxonomic difficulties with some taxa (particularly invertebrates) prevent even professional biologists from using them as indicators (Gerlach et al. 2013). Among the taxa that I analyzed, 5 (Odonata, Diptera, Orthoptera, Hymenoptera, Araneae) appear to show the types of consistent responses required of an indicator. Some of these groups, such as the Syrphidae within the Diptera and Bombus sp. in the Hymenoptera, consist of large and diverse taxa, and specieslevel data sets that may be of interest are provided in Table S2.

The mechanisms underlying responses to climate change are perhaps best understood within the Odonata (among the 5 groups listed above). Observational studies of patterns in historical records in relation to phenology (Hassall et al. 2007, Dingemanse and Kalkman 2008) and distributions (Hickling et al. 2005, Hassall and Thompson 2010) have been followed by experimental studies done to identify links between increasing temperature and life-history timing (Braune et al. 2008, Richter et al. 2008) and the key components of thermal biology that modulate range expansions (Stoks and De Block 2011, Nilsson-Örtman et al. 2012). Moreover, mechanistic understanding of temperaturesize relationships in this taxon is increasing (Hassall 2013), and odonates are accessible to citizen scientists by virtue of their size and charisma. My results support previous suggestions that too little is known to identify specific taxa as adequate indicators of climate-change responses at a broader scale (Andrew et al. 2013). However, I propose that the Odonata be given greater attention as potential indicators because of their strong and well described macroecological responses, key ecological roles in aquatic and terrestrial systems, and their growing utility as models in physiological and genetic studies.

\section{Conclusion}

My results contribute to our knowledge of the utility of biological records in studies of climate-induced macroecological responses. Taxa are highly variable in the degree to which they respond to climate, and some taxa (particularly invertebrates) show strong phenological advances and poleward range shifts. In some groups, a trade-off appears to exist between temporal and spatial responses. However, species of Odonata and Orthoptera with greater poleward range shifts also appear to show greater phenological advances. This finding suggests that these thermophilic taxa may exhibit complementary, multimodal responses to climate. The variability among taxa indicates that the use of a single taxon to represent the wider responses of 
biota is unwise because different taxa may have evolved different methods for coping with environmental change. However, the Odonata appear to respond to climate change in both space and time, are amenable to study in the laboratory and in the field by experts and citizen scientists and, therefore, have great potential as a biological proxy for climate change.

\section{ACKNOWLEDGEMENTS}

I would like to acknowledge the tremendous work done by (often volunteer) recording schemes that have contributed data to this study: Isopoda (interim data set), Crayfish Data for Britain and Ireland, Mosquito Recording Scheme, Hoverfly Recording Scheme, Tachinid Recording Scheme, Cranefly Records for Great Britain, Aquatic Heteroptera Dataset, Water Bug data for Great Britain, Tick distribution for the British Isles, Lacewings and Allied Insects, Grasshopper and Cricket Records, Pseudoscorpion Recording Scheme, Database for the Atlas of Freshwater Fishes, Bees, Wasps and Ants Recording Society, Riverfly Recordings, ARC Database, Amphibians and Reptiles Dataset, British Arachnological Society's Spider Recording Scheme, Opiliones Dataset, Collembola Recording Scheme, Ground Beetle Recording Scheme, Cerambycidae Dataset, Ciidae Records, Coccinellidae Data, Derek Lott Coleoptera Dataset, and Water Beetle Surveys from Britain and Ireland.

\section{LITERATURE CITED}

$\rightarrow$ Amano, T., R. P. Freckleton, S. A. Queenborough, S. W. Doxford, R. J. Smithers, T. H. Sparks, and W. J. Sutherland. 2014. Links between plant species' spatial and temporal responses to a warming climate. Proceedings of the Royal Society of London Series B: Biological Sciences 281:20133017.

$\rightarrow$ Andrew, N. R., S. J. Hill, M. Binns, M. H. Bahar, E. V. Ridley, M.-P. Jung, C. Fyfe, M. Yates, and M. Khusro. 2013. Assessing insect responses to climate change: What are we testing for? Where should we be heading? PeerJ 1:e11.

$\rightarrow$ Angert, A. L., L. G. Crozier, L. J. Rissler, S. E. Gilman, J. J. Tewksbury, and A. J. Chunco. 2011. Do species' traits predict recent shifts at expanding range edges? Ecology Letters $14: 677-689$.

$\rightarrow$ Araújo, M. B., M. Cabezas, W. Thuiller, L. Hannah, and P. H. Williams. 2004. Would climate change drive species out of reserves? An assessment of existing reserve-selection methods. Global Change Biology 10:1618-1626.

Ashworth, A. C. 1997. The response of beetles to Quaternary climate changes. Pages 119-127 in B. Huntley, W. Cramer, A. V. Morgan, H. C. Prentice, and J. R. M. Allen (editors). Past and future rapid environmental changes: the spatial and evolutionary responses of terrestrial biota. Springer, Berlin, Germany.

$\rightarrow$ Balmford, A. 1996. Extinction filters and current resilience: the significance of past selection pressures for conservation biology. Trends in Ecology and Evolution 11:193-196.

Bates, D., M. Maechler, and B. Bolker. 2011. lme4: linear mixedeffects models using S4 classes. R package version 0.99937539. R Project for Statistical Computing, Vienna, Austria. (Available from: http://CRAN.R-project.org/package=lme4) $\rightarrow$ Beebee, T. J. C., and R. A. Griffiths. 2005. The amphibian decline crisis: a watershed for conservation biology? Biological Conservation 125:271-285.

$\rightarrow$ Bishop, T. R., M. S. Botham, R. Fox, S. R. Leather, D. S. Chapman, and T. H. Oliver. 2013. The utility of distribution data in predicting phenology. Methods in Ecology and Evolution 4:1024-1032.

Böhm, M., B. Collen, J. E. M. Baillie, P. Bowles, J. Chanson, N. Cox, G. Hammerson, M. Hoffmann, S. R. Livingstone, M. Ram, A. G. J. Rhodin, S. N. Stuart, P. P. van Dijk, B. E. Young, L. E. Afuang, A. Aghasyan, A. García, C. Aguilar, R. Ajtic, F. Akarsu, L. R. V. Alencar, A. Allison, N. Ananjeva, S. Anderson, C. Andrén, D. Ariano-Sánchez, J. C. Arredondo, M. Auliya, C. C. Austin, A. Avci, P. J. Baker, A. F. Barreto-Lima, C. L. Barrio-Amorós, D. Basu, M. F. Bates, A. Batistella, A. Bauer, D. Bennett, W. Böhme, D. Broadley, R. Brown, J. Burgess, A. Captain, S. Carreira, M. del Rosario Castañeda, F. Castro, A. Catenazzi, J. R. Cedeño-Vázquez, D. G. Chapple, M. Cheylan, D. F. Cisneros-Heredia, D. Cogalniceanu, H. Cogger, C. Corti, G. C. Costa, P. J. Couper, T. Courtney, J. Crnobrnja-Isailovic, P.-A. Crochet, B. Crother, F. Cruz, J. C. Daltry, R. J. R. Daniels, I. Das, A. de Silva, A. C. Diesmos, L. Dirksen, T. M. Doan, C. K. Dodd Jr, J. S. Doody, M. E. Dorcas, J. D. de Barros Filho, V. T. Egan, E. H. El Mouden, D. Embert, R. E. Espinoza, A. Fallabrino, X. Feng, Z.-J. Feng, L. Fitzgerald, O. Flores-Villela, F. G. R. França, D. Frost, H. Gadsden, T. Gamble, S. R. Ganesh, M. A. Garcia, J. E. GarcíaPérez, J. Gatus, M. Gaulke, P. Geniez, A. Georges, J. Gerlach, S. Goldberg, J.-C. T. Gonzalez, D. J. Gower, T. Grant, E. Greenbaum, C. Grieco, P. Guo, A. M. Hamilton, K. Hare, S. B. Hedges, N. Heideman, C. Hilton-Taylor, R. Hitchmough, B. Hollingsworth, M. Hutchinson, I. Ineich, J. Iverson, F. M. Jaksic, R. Jenkins, U. Joger, R. Jose, Y. Kaska, U. Kaya, J. S. Keogh, G. Köhler, G. Kuchling, Y. Kumlutaş, A. Kwet, E. La Marca, W. Lamar, A. Lane, B. Lardner, C. Latta, G. Latta, M. Lau, P. Lavin, D. Lawson, M. LeBreton, E. Lehr, D. Limpus, N. Lipczynski, A. S. Lobo, M. A. López-Luna, L. Luiselli, V. Lukoschek, M. Lundberg, P. Lymberakis, R. Macey, W. E. Magnusson, D. L. Mahler, A. Malhotra, J. Mariaux, B. Maritz, O. A. V. Marques, R. Márquez, M. Martins, G. Masterson, J. A. Mateo, R. Mathew, N. Mathews, G. Mayer, J. R. McCranie, G. J. Measey, F. Mendoza-Quijano, M. Menegon, S. Métrailler, D. A. Milton, C. Montgomery, S. A. A. Morato, T. Mott, A. Muñoz-Alonso, J. Murphy, T. Q. Nguyen, G. Nilson, C. Nogueira, H. Núñez, N. Orlov, H. Ota, J. Ottenwalder, T. Papenfuss, S. Pasachnik, P. Passos, O. S. G. Pauwels, N. PérezBuitrago, V. Pérez-Mellado, E. R. Pianka, J. Pleguezuelos, C. Pollock, P. Ponce-Campos, R. Powell, F. Pupin, G. E. Quintero Díaz, R. Radder, J. Ramer, A. R. Rasmussen, C. Raxworthy, R. Reynolds, N. Richman, E. L. Rico, E. Riservato, G. Rivas, P. L. B. da Rocha, M.-O. Rödel, L. Rodríguez Schettino, W. M. Roosenburg, J. P. Ross, R. Sadek, K. Sanders, G. SantosBarrera, H. H. Schleich, B. R. Schmidt, A. Schmitz, M. Sharif, G. Shea, H.-T. Shi, R. Shine, R. Sindaco, T. Slimani, R. Somaweera, S. Spawls, P. Stafford, R. Stuebing, S. Sweet, E. Sy, H. J. Temple, M. F. Tognelli, K. Tolley, P. J. Tolson, B. Tuniyev, S. Tuniyev, N. Üzüm, G. van Buurt, M. Van Sluys, A. Velasco, M. Vences, M. Veselý, S. Vinke, T. Vinke, G. Vogel, M. Vogrin, R. C. Vogt, O. R. Wearn, Y. L. Werner, M. J. Whit- 
ing, T. Wiewandt, J. Wilkinson, B. Wilson, S. Wren, T. Zamin, K. Zhou, and G. Zug. 2013. The conservation status of the world's reptiles. Biological Conservation 157:372-385.

$\rightarrow$ Braune, E., O. Richter, D. Söndgerath, and F. Suhling. 2008. Voltinism flexibility of a riverine dragonfly along thermal gradients. Global Change Biology 14:470-482.

Cannell, M. G. R., J. P. Palutikof, and T. H. Sparks. 1999. Indicators of climate change in the UK. Department of the Environment, Transport and the Regions, London, UK. (Available from: http://www.ecn.ac.uk/iccuk/)

$\rightarrow$ Caro, T. M., and G. O'Doherty. 1999. On the use of surrogate species in conservation biology. Conservation Biology 13: 805-814.

Coope, G. R. 1995. The effects of Quaternary climatic changes in insect populations: lessons from the past. Pages 30-48 in R. Harrington and N. E. Stork (editors). Insects in a changing environment. Academic Press, San Diego, California.

$\rightarrow$ Coope, G. R. 2004. Several million years of stability among insect species because of, or in spite of, Ice Age climatic instability? Philosophical Transactions of the Royal Society of London Series B: Biological Sciences 359:209-214.

Cordoba-Aguilar, A. 2008. Dragonflies and damselflies: model organisms for ecological and evolutionary research. Oxford University Press, Oxford, UK.

$\rightarrow$ Crimmins, S. M., S. Z. Dobrowski, J. A. Greenberg, J. T. Abatzoglou, and A. R. Mynsberge. 2011. Changes in climatic water balance drive downhill shifts in plant species' optimum elevations. Science 331:324-327.

$\rightarrow$ Crimmins, T. M., M. A. Crimmins, and C. D. Bertelsen. 2009. Flowering range changes across an elevation gradient in response to warming summer temperatures. Global Change Biology 15:1141-1152.

Crutzen, P. J. 2006. The "Anthropocene". Pages 13-18 in E. Ehlers and T. Krafft (editors). Earth system science in the Anthropocene. Springer, Berlin, Germany.

$\rightarrow$ Daufresne, M., and P. Boët. 2007. Climate change impacts on structure and diversity of fish communities in rivers. Global Change Biology 13:2467-2478.

$\rightarrow$ Daufresne, M., K. Lengfellner, and U. Sommer. 2009. Global warming benefits the small in aquatic ecosystems. Proceedings of the National Academy of Sciences of the United States of America 106:12788-12793.

$\rightarrow$ De Block, M., and R. Stoks. 2003. Adaptive sex-specific life history plasticity to temperature and photoperiod in a damselfly. Journal of Evolutionary Biology 16:986-995.

$\rightarrow$ Diamond, S. E., A. M. Frame, R. A. Martin, and L. B. Buckley. 2011. Species' traits predict phenological responses to climate change in butterflies. Ecology 92:1005-1012.

$\rightarrow$ Dingemanse, N. J., and V. J. Kalkman. 2008. Changing temperature regimes have advanced the phenology of Odonata in the Netherlands. Ecological Entomology 33:394-402.

$\rightarrow$ Durance, I., and S. J. Ormerod. 2009. Trends in water quality and discharge confound long-term warming effects on river macroinvertebrates. Freshwater Biology 54:388-405.

$\rightarrow$ Fleishman, E., and D. D. Murphy. 2009. A realistic assessment of the indicator potential of butterflies and other charismatic taxonomic groups. Conservation Biology 23:1109-1116.

Fletcher, T. D. 2010. psychometric: applied psychometric theory. $\mathrm{R}$ package version 2.2. $\mathrm{R}$ Project for Statistical Computing,
Vienna, Austria. (Available from: http://CRAN.R-project.org /package $=$ psychometric)

$\rightarrow$ Gardner, J. L., A. Peters, M. R. Kearney, L. Joseph, and R. Heinsohn. 2011. Declining body size: a third universal response to warming? Trends in Ecology and Evolution 26:285-291.

$\rightarrow$ Gerlach, J., M. Samways, and J. Pryke. 2013. Terrestrial invertebrates as bioindicators: an overview of available taxonomic groups. Journal of Insect Conservation 17:831-850.

Goertzen, D., and F. Suhling. 2013. Promoting dragonfly diversity in cities: major determinants and implications for urban pond design. Journal of Insect Conservation 17:399-409.

$\rightarrow$ Harvell, C. D., C. E. Mitchell, J. R. Ward, S. Altizer, A. P. Dobson, R. S. Ostfeld, and M. D. Samuel. 2002. Climate warming and disease risks for terrestrial and marine biota. Science 296:2158-2162.

$\rightarrow$ Hassall, C. 2013. Time stress and temperature explain continental variation in damselfly body size. Ecography 36:894-903.

$\rightarrow$ Hassall, C., and D. J. Thompson. 2008. The impacts of environmental warming on Odonata: a review. International Journal of Odonatology 11:131-153.

$\rightarrow$ Hassall, C., and D. J. Thompson. 2010. Accounting for recorder effort in the detection of range shifts from historical data. Methods in Ecology and Evolution 1:343-350.

$\rightarrow$ Hassall, C., D. J. Thompson, G. C. French, and I. F. Harvey. 2007. Historical changes in the phenology of British Odonata are related to climate. Global Change Biology 13:933-941.

$\rightarrow$ Hickling, R., D. B. Roy, J. K. Hill, R. Fox, and C. D. Thomas. 2006. The distributions of a wide range of taxonomic groups are expanding polewards. Global Change Biology 12:1-6.

$\rightarrow$ Hickling, R., D. B. Roy, J. K. Hill, and C. D. Thomas. 2005. A northward shift of range margins in British Odonata. Global Change Biology 11:502-506.

$\rightarrow$ Huber, M., and R. Knutti. 2011. Anthropogenic and natural warming inferred from changes in Earth's energy balance. Nature Geoscience 5:31-36.

IPCC (Intergovernmental Panel on Climate Change) 1996. Climate change 1995: the science of climate change. Contribution of working group I to the $2^{\text {nd }}$ assessment report of the IPCC. Cambridge University Press, New York.

$\rightarrow$ Johansson, F. 2003. Latitudinal shifts in body size of Enallagma cyathigerum (Odonata). Journal of Biogeography 30:29-34.

$\rightarrow$ Li, M.-H., N. Kräuchi, and S.-P. Gao. 2006. Global warming: can existing reserves really preserve current levels of biological diversity? Journal of Integrative Plant Biology 48:255-259.

$\rightarrow$ MacDougall, A. S., and R. Turkington. 2005. Are invasive species the drivers or passengers of change in degraded ecosystems? Ecology 86:42-55.

$\rightarrow$ Menzel, A., T. H. Sparks, N. Estrella, E. Koch, A. Aasa, R. Ahas, K. Alm-Kübler, P. Bissolli, O. G. Braslavská, A. Briede, F. M. Chmielewski, Z. Crepinsek, Y. Curnel, A. Dahl, C. Defila, A. Donnelly, Y. Filella, K. Jatczak, F. Måge, A. Mestre, O. Nordli, J. Peñuelas, P. Pirinen, V. Remisova, H. Scheifinger, M. Striz, A. Susnik, A. J. H. van Vliet, F. E. Wielgolaski, S. Zach, A. Zust. 2006. European phenological response to climate change matches the warming pattern. Global Change Biology 12: 1969-1976.

$\rightarrow$ Moussus, J.-P., R. Julliard, and F. Jiguet. 2010. Featuring 10 phenological estimators using simulated data. Methods in Ecology and Evolution 1:140-150. 
$\rightarrow$ Nilsson-Örtman, V., R. Stoks, M. De Block, and F. Johansson. 2012. Generalists and specialists along a latitudinal transect: patterns of thermal adaptation in six species of damselflies Ecology 93:1340-1352.

$\rightarrow$ Parmesan, C. 2006. Ecological and evolutionary responses to recent climate change. Annual Review of Ecology, Evolution, and Systematics 37:637-669.

$\rightarrow$ Parmesan, C., and G. Yohe. 2003. A globally coherent fingerprint of climate change impacts across natural systems. Nature 421:37-42.

$\rightarrow$ Pearson, D. L. 1994. Selecting indicator taxa for the quantitative assessment of biodiversity. Philosophical Transactions of the Royal Society of London Series B: Biological Sciences 345:75-79.

$\rightarrow$ Pearson, R. G., J. C. Stanton, K. T. Shoemaker, M. E. AielloLammens, P. J. Ersts, N. Horning, D. A. Fordham, C. J Raxworthy, H. Y. Ryu, and J. McNees. 2014. Life history and spatial traits predict extinction risk due to climate change. Nature Climate Change 4:217-221.

$\rightarrow$ Pöyry, J., M. Luoto, R. K. Heikkinen, M. Kuussaari, and K. Saarinen. 2009. Species traits explain recent range shifts of Finnish butterflies. Global Change Biology 15:732-743.

$\rightarrow$ Pressey, R. L., M. Cabeza, M. E. Watts, R. M. Cowling, and K. A. Wilson. 2007. Conservation planning in a changing world. Trends in Ecology and Evolution 22:583-592.

$\rightarrow$ Raebel, E. M., T. Merckx, R. E. Feber, P. Riordan, D. W. Macdonald, and D. J. Thompson. 2012. Identifying highquality pond habitats for Odonata in lowland England: implications for agri-environment schemes. Insect Conservation and Diversity 5:422-432.

$\rightarrow$ Richter, O., F. Suhling, O. Müller, and D. Kern. 2008. A model for predicting the emergence of dragonflies in a changing climate. Freshwater Biology 53:1868-1880.

$\rightarrow$ Sala, O. E., F. S. Chapin, J. J. Armesto, E. Berlow, J. Bloomfield, R. Dirzo, E. Huber-Sanwald, L. F. Huenneke, R. B. Jackson, A Kinzig, R. Leemans, D. M. Lodge, H. A. Mooney, M. Oesterheld, N. L. Poff, M. T. Sykes, B. H. Walker, M. Walker, and D. H. Wall. 2000. Global biodiversity scenarios for the year 2100. Science 287:1770-1774.

$\rightarrow$ Scheipl, F., S. Greven, and H. Kuechenhoff. 2008. Size and power of tests for a zero random effect variance or polynomial regression in additive and linear mixed models. Computational Statistics \& Data Analysis 52:3283-3299.

Schwarzer, G. 2014. meta: meta-analysis with R. R package version 3.2-1. R Project for Statistical Computing, Vienna, Austria (Available from: http://CRAN.R-project.org/package=meta)

$\rightarrow$ Sheridan, J. A., and D. Bickford. 2011. Shrinking body size as an ecological response to climate change. Nature Climate Change 1:401-406

$\rightarrow$ Silvertown, J. 2009. A new dawn for citizen science. Trends in Ecology and Evolution 24:467-471.

$\rightarrow$ Stoks, R., and M. De Block. 2011. Rapid growth reduces cold resistance: evidence from latitudinal variation in growth rate cold resistance and stress proteins. PLoS ONE 6:e16935. $\rightarrow$ Thackeray, S. J., T. H. Sparks, M. Frederiksen, S. Burthe, P. J. Bacon, J. R. Bell, M. S. Botham, T. M. Brereton, P. W. Bright, L. Carvalho, T. Clutton-Brock, A. Dawson, M. Edwards, J. M. Elliott, R. Harrington, D. Johns, I. D. Jones, J. T. Jones, D. I. Leech, D. B. Roy, W. A. Scott, M. Smith, R. J. Smithers, I. J. Winfield, and S. Wanless. 2010. Trophic level asynchrony in rates of phenological change for marine, freshwater and terrestrial environments. Global Change Biology 16:3304-3313.

$\rightarrow$ Thomas, C. D., A. Cameron, R. E. Green, M. Bakkenes, L. J. Beaumont, L. Hughes, Y. C. Collingham, B. Huntley, B. F. N. Erasmus, M. Ferreira de Siqueira, A. Grainger, L. Miles, O. L. Phillips, L. Hannah, A. S. Van Jaarsveld, G. F. Midgley, M. A. Ortega-Huerta, A. T. Peterson, and S. E. Williams. 2004. Extinction risk from climate change. Nature 427:145148.

$\rightarrow$ Travis, J. M. J. 2003. Climate change and habitat destruction: a deadly anthropogenic cocktail. Proceedings of the Royal Society of London Series B: Biological Sciences 270:467-473.

Tremblay, A., and J. Ransijn. 2013. LMERConvenienceFunctions: a suite of functions to back-fit fixed effects and forward-fit random effects, as well as other miscellaneous functions. $R$ package version 2.5. R Project for Statistical Computing, Vienna, Austria. (Available from: http://CRAN.R-project.org /package=LMERConvenienceFunctions)

UK Meteorological Office Hadley Centre. 2006. Historical Central England Temperature (CET) Data. British Atmospheric Data Centre, Hadley, UK. (Available from: http://badc.nerc .ac.uk/data/cet/)

$\rightarrow$ Van Praet, N., A. Covaci, J. Teuchies, L. De Bruyn, H. Van Gossum, R. Stoks, and L. Bervoets. 2012. Levels of persistent organic pollutants in larvae of the damselfly Ischnura elegans (Odonata, Coenagrionidae) from different ponds in Flanders, Belgium. Science of the Total Environment 423:162-167.

$\rightarrow$ Visser, M. E., L. J. M. Holleman, and P. Gienapp. 2006. Shifts in caterpillar biomass phenology due to climate change and its impact on the breeding biology of an insectivorous bird. Oecologia (Berlin) 147:164-172.

$\rightarrow$ Walther, G. R., E. Post, P. Convey, A. Menzel, C. Parmesan T. J. C. Beebee, J. M. Fromentin, O. Hoegh-Guldberg, and F. Bairlein. 2002. Ecological responses to recent climate change. Nature 416:389-395.

$\rightarrow$ Watts, P. C., J. R. Rouquette, I. J. Saccheri, S. J. Kemp, and D. J. Thompson. 2004. Molecular and ecological evidence for small-scale isolation by distance in an endangered damselfly, Coenagrion mercuriale. Molecular Ecology 13:2931-2945.

$\rightarrow$ Willott, S. J., and M. Hassall. 1998. Life-history responses of British grasshoppers (Orthoptera: Acrididae) to temperature change. Functional Ecology 12:232-241.

$\rightarrow$ Winder, M., and D. E. Schindler. 2004. Climate change uncouples trophic interactions in an aquatic ecosystem. Ecology 85:2100-2106

$\rightarrow$ Zhu, K., C. W. Woodall, and J. S. Clark. 2012. Failure to migrate: lack of tree range expansion in response to climate change. Global Change Biology 18:1042-1052. 